clear that Dr. Rawson, who has one particular reason for being especially conscious of the problems of the deaf, was assigned to her investigation with my approval and that her report was published because I believed it to be an unusually good piece of work worthy of wider readership.-I am, etc.,

G. E. GODBER Chief Medical Officer Department of Health and Social Security,

1 Department of Health and Social Security, into the Promotion of Research. Enquiry H.M.S.O., 1973.

SIR,-On reading the report on deafness by Dr. Annette Rawson ${ }^{1}$ I was impressed by her authoritative opinion that the problems of the deaf adult are still neglected over much of this country. No reliable figures of the prevalence and incidence of acouiring hearing loss are available, little is known about causes, diagnostic tests are often inadequate for appropriate prescription of aids, and insufficient time is spent on teaching patients how to use them. Many people thus remain undiagnosed or do not use their aids.

Most doctors would readily agree that this is an alarming picture and thus the reoommendations of the report, with its accent on a multidisciplinary approach, would, one imagines, have been welcomed. The letter (25 August, p. 455) signed by 11 members of various departments audiology denigrates her report in a destructive manner, with pedantic references to terminology, and points up what would appear to be possible errors of little consequence.

I would respectfully suggest to the signatories that it is perhaps in part owing to their "errors of both commission and omission" that such "persistent pessimism" as Dr. Rawson's seems justified. She has a profound understanding of the problems of the deaf; she is deaf herself and has fought to overcome this so that she is now able to make such a fine contribution as this report. -I am, etc.,

Glyncorrwg, Glam

IAN K. SCOTT

1 Department of Health and Social Security, Deafness: Report of a Departmental Enquiry into the
Promotion of Research. London, H.M.S.O.,
1973.

\section{American Medicine}

SIR,-Recent discussion in your columns of the relative "inferiority" or "superiority" of American and British medicine prompts me to add some opinions viewed from the less prestigious level of family practice. I have been in the U.S. for nine months, looking particularly at the training of medical students, the systems of practice, and health care delivery and the following points are, I believe, important.

(1) "Superior" medicine in the U.S. is characterized by intensive and thorough investigation of the patient. It is widespread even in small hospitals and supports the view of Dr. I. L. Gregory (7 July, p. 50). Unfortunately, expensively equipped small hospitals can exist side by side in competition with each other. Their equipment often remains under-used and the patients are often over-investigated.

(2) The distribution of specialists through- out the U.S. is related more to the physicians' needs than to those of the patient. A poor county or town will not attract the specialist. A wealthy area may well be served by an excessive number of specialists-for instance, neurosurgeons who rapidly develop a shortage of suitable patients. In order to maintain their competence and income these surgeons may overreat their patients.

(3) Though "superior" medicine may be provided to hospitalized patients, the medical care system can fall apart on discharge. There may be no family physioian available for the patient at home, no adequate public health nurse (distriot nurse), and no access to primary care other than the hospital casualty department.

(4) I disagree with Dr. Gregory that medical costs are adequately covered by insurance and the Medicare-Medicaid programmes. Outpatient costs are frequently not covered by insurance, and the MedicareMedicaid programmes are related to the wealth of the area in which the patient lives. A poor county has to match the Medicaid funds provided by the Government. For instance, a local agricultural worker at this hospital was unable to obtain Medicaid. He was earning $\$ 1,800$ (about $\$ 700$ ) per annum. $\$ 100$ more than the level at which Medicaid is provided. His disease, diabetes, was costing him $\$ 600$ ( $£ 240$ ) annually, leaving him and his family $£ 360$ to live on for one year.

In general, physicians in the U.S. have higher standards than their counterparts in the U.K. But these standards apply only to the specific practice of scientific medicine. One must therefore ask, what is good medicine and who should make this judgement? Is it to be high-quality care, lacking in continuity and available only to certain portions of the population as in the U.S.? Or is it the provision of a lower standard with open access for all using an integrated health system? Certainly the American people are discontented with the service they are receiving. On the other hand, the British public, supposedly satisfied with their health system, may be unaware of the improvements of standards that are possible in the National Health Service.-I am, etc.,

Family Practice Unit,

Peter CURTis

North Carolina Memorial Hospital, University of North Carolina,

Chapel Hill, N.C.

\section{Endotoxic Shock after Transhepatic Cholangiography}

SIR,-The danger of endotoxic shook as a complication of transhepatic cholangiography is well illustrated by Mr. M. R. B. Keighley and others (21 July, p. 147). We wish to report a parallel occurrence in a patient with a bile duct carcinoma rather than calculi and survival from the episode of endotoxic shock for four months.

A 54-year-old man presented with obstructive jaundice, confirmed at necropsy 16 months later as being due to a carcinoma of the common hepatic duct. At exploration originally cannulation of the duct had been attempted without success and a liver biopsy revealed merely pericholangitis. A biliary fistula resulted and anastomosis of the track to a jejunal loop relieved all the symptoms, though mild jaundice persisted. The biliary fistula recurred spontaneously a year later and a percutaneous transhepatic cholangiogram was performed without antibiotic cover. Within two hours the patient developed rigors, fever, tachycardia, and hypotension. Culture of the bile and blood grew Escherichia coli of similar sensitivity and the systolic blood pressure remained below $100 \mathrm{~mm} \mathrm{Hg}$ for 14 hours. Treatment with hydrocortisone, gentamicin (to which the organism proved sensitive), isoprenaline, blood transfusion, and mannitol ( $50 \mathrm{~g}$ total dose) resulted in clinical improvement and ultimate relief of the oliguria. A Longmire procedure was then carried out, as the cholangiogram showed a communication between the right and left hepatic duct systems. The patient left hospital in three weeks but died four months later of cholangitis and liver failure. Necropsy confirmed these findings with histological confirmation of a locally extensive bile duct carcinoma at the junction of the right and left hepatic ducts.

Contamination of the biliary tree was possibly present in this patient before the transhepatic cholangiogram. If so he had no signs or symptoms of it for a year, but the appearance of a biliary fistula a few days before the cholangiogram was clearly significant. The episode of endotoxic shock, however, was clearly a sequel of the cholangiogram, and it is possible that the use of isoprenaline and early mannital infusion, as recommended by Dawson, 1 contributed to recovery by shortening the time of oliguria. The haphazard use of "prophylatic" antibiotics before cholangiography does not appear justified on two counts-firstly, that many Gram-negative organisms are resistant to the non-toxic broad-spectrum antibiotics, and, secondly, that it is questionable whether antibiotics reach an obstructed biliary system. ${ }^{2}$-We are, etc.,

Roger LALLEMAND GUY BLACKBURN

Guy's Hospital

1 Dawson, J. L., Annals of the Royal College of Mortimer, P. R., Mackie, D. B., and Haynes, S., 3 Scott, A. J., Gut, 1971, 12, 487 .

\section{Higher Medical Training in Relation to} Research

SIR,-There is some anxiety that the training programmes recommended by the Joint Committee on Higher Medical Training may have an adverse effect on research. The committee intend that research should be encouraged and full recognition should be given to its importance in training. However, a clinical research worker should be clinically competent and this is essential if he is to gain consultant status in the Health Service.

Most clinical research workers will seek accreditation in general medicine or in the clinical specialty with which they are concerned. A young doctor completing the M.R.C.P. within two years after the preregistration year could engage in some clinical research in the third year of general professional training. He then could go on to hold, for examole, a Medical Research Council olinical research fellowship in a basic science department for two years without any responsibility for patient care and return to an academic appointment with clinical responsibility to continue research in the same field. If this appointment provided appropriate clincal experience and responsibility and was held for at least two years the trainee would be eligible for consideration for accreditation.

We also intend that for those seeking accreditation in more specialized fields full 
account should be taken of research in a national, multi-centre data for I.U.D. assessrelevant basic science. We recognize that a flexible system must operate. Some investigators will undoubtedly follow unorthodox paths and we do not wish to discourage this. Their accreditation could be considered on merit suggested in the heavy type on p. 8 of the First Report of the J.C.H.M.T. This reads as follows: "It is not intended, nor is it possible, to lay down rigid prescriptions for the training of specialists. Any suggested framework in the following schedules should be interpreted flexibly, allowing for variations in time, for the special needs of individuals, and for local circumstances."-I am, etc.,

\section{J. Halliday Croom} Joint Committee on Higher Medical Training Royal College of Physicians,

\section{Clinical Experience with the Dalkon Shield}

SIR, - With reference to the paper by $\mathrm{Mr}$. R. W. Jones and others (21 July, p. 143) I agree wholeheartedly with the statement that independemt study of the Dalkon Shield's effectiveness is desirable. Such a study has been under way for some 30 months, controlled by the Family Planning Research Unit at Exeter University, who have accumulated data from some 10-12 family planning clinics. The initial results for one year up to September 1972, compiled by the life table method, have now been published. 12 These data, from a variety of clinics and involving many doctors of varying grades of experience, produced event rates as follows: pregnancy rate $3.8 \%$; expulsion rate, $3.9 \%$; bleeding/pain removal rate, $4.6 \%$. You will see that in each case these multi-centre rates were better than those produced by Mr. Jones and his colleagues.

Now why should this be? Close examination of these authors' paper discloses the following points: (1) Twenty insentions were performed by doctors who are described as "learning the technique." (2) Thirty-one insertions were performed at the time of pregnancy termination. It is surely important that we have some more information about this group, because it is well known that the insertion of an intrauterine device in this situation depends on the duration of the pregnancy at termination, the type of technique employed, and the success of the evacuation procedure. (3) Only two small shields were used and yet there were 18 nulliparous women in the series. I would expect that there would be a much higher chance of complications when a standard-size shield was inserted into a nulliparous cervix and I would postulate that some of the Dalkon Shields at least that were expelled or were removed probably fell into this category of inappropriate ahoice of device. (4) The data appear to have been analysed not by the life table method, but presumably with the Pearl formula, which is now accepted as being an out-of-date method of analysis which invariably produces poor results from the event rate point of view in the early stages of a study, but much better rates as time goes on.

I do feel, however, that this paper helps to support the suggestion that the use of A. H. Robins Co. Ltd. ment is obligatory. I consider that the data from Exeter are more meaningful, as being representative of the future I.U.D.-using doctor in general, than those from any single-centre study.-I am, etc.,

\section{J. S. TEMPLETON}

Horsham, Sussex

1 The Dalkon Shield. Family Planning Research of Exeter 1973 . 2 Snowden, R., and Williams, M., Contraception,
1973, 7, 91.

SIR, - With reference to the paper by $M r$. R. W. Jones and others (21 July, p. 143) I would like to report the following case. A 28-year-old para 1 was fitted with a Dalkon Shield eight weeks after the birth of her baby. She attended for follow-up two months later and the shield was satisfactorily in place. Two weeks later she attended complaining of suprapubic pains and backache and requested removal of the shield.

The shield was still in place. When the tail attached to the shield was pulled the patient experienced severe pelvic pain and felt faint. It was decided to remove the shield under general anaesthesia. This was achieved easily and curettage was also performed. Because of the severe pain at the initial attempted removal of the shield laparoscopy was performed to exclude a uterine perforation. This showed a left tubal pregnancy with an intact uterus. Laparotomy was performed and the left tube removed, following which the patient made an uneventuful recovery.

This illustrates that pain on removal of the shield may be associated with ectopic pregnancy.-I am, etc.,

J. D. O'Donovan

King Bdward Memorial Hospital for Women,

Wubiaco, Wustralia

the hospital team, the general practitioner, and the ancillary services thereby related. Early discharge has already encouraged this liaison and has in no way prejudiced the patient's safety when the time for monitoring has passed.

There can be little place for expansion of the group of cases judged suitable for day operations if selection is made on clinical grounds. The careful hour-by-hour monitoring of postoperative patients by those with experience and skill cannot be safely replaced by the diffuse and intermittent care of home circumstances, by staff variable in skill, in personage, and in enthusiasm. Nor does a deputizing service provide a suitable source of supervision on the nights of the practitioner's relief or compare with the vigilance of house surgeons on the spot. One can only deduce that quality, facilities, and safety are to be sacrificed for statistics. It is readily understandable that the Department of Health is only too happy to seize upon such an easy way out of the waiting list situation which they have failed to solve in the past by the provision of the necessary resources.

What of the consultant's responsibility? The law might well consider his field of responsibility expanded through his operative commitment to cover the care of his patient by those or their deputies whom he has never seen. The free access of patients to legal aid might deter many surgeons from such a commitment. What of the general practitioner's responsibility? All is well that ends well, but that which does not end well may be a very invidious chapter indeed.

Reduction of waiting lists at the price of a second-class standard of patient care is unacceptable and should be rejected at any level. In the opinion of many of us, those concerned should think very hard and think again before materially changing their selection of patients suitable for day surgery.-I am, etc.,

Alistair Cassie

Burnley General Hospital,
Burnley, Lancs

\section{Surgery on Day Patients}

SIR,-Those who have read $\operatorname{HM}(73) 32$,

"Arrangements for the Care of Persons Attending Hospital for Surgical Procedures as Day Patients," have justification for a deep sense of unease derived from this superficial and naive document. Profoundities in regard to the "significant and continuous contribution" which day surgery may make "to the reduction and control of surgical waiting lists and ... demand on inpatient facilities" are bandied about, as are references to its being "welcome both to patients and staff." What then have we surgeons been playing at in the light of such revelations from the Elephant and Castle? Might there be another side to the coin? Have we not sufficient arithmetical ability to deduce that waiting lists would shrink if large numbers of operations were done as ourpatient procedures? Why then do many of us reject a material expansion of this procedure? The answer is simple and in its simplicity so complex-safety and quality of care. Where these are not prejudiced such arrangements are generally already implemented and based on an understanding which has grown up between

SIR,-Two valuable surveys of G.P. deputizing services have recently been published. Using calculations based on indirect evidence, Dr. B. T. Williams and others (10 March, p. 593) estimated that the Sheffield service handled between $0.4 \%$ and $2.0 \%$ of all calls for those G.P. who subscribed to it and between $1 \%$ and $17 \%$ of their home visits. They concluded that "at this level of activity the concept of 'personal doctoring' was not threatened." In Nottingham the same authors ${ }^{1}$ found that the outcome of referral of patients to hospital by deputizing services and by G.P.s was the same-as estimated by the proportion actually admitted, their length of stay, the proportion operated on, and their mortality. They concluded that "familianity with patients' past medical histories and general circumstances does not appear to be crucial in determining the proper use of hospital resources for emergencies."

Little has been written of the views of patients and deputizing doctors themselves. I have worked for a large deputizing service and for several years in hospital. Perhaps I 